\title{
Open Access: a Primer from UKRN
}

Authors (Z-A): Sally Rumsey, Carole Lunny, Bradley Kennedy.

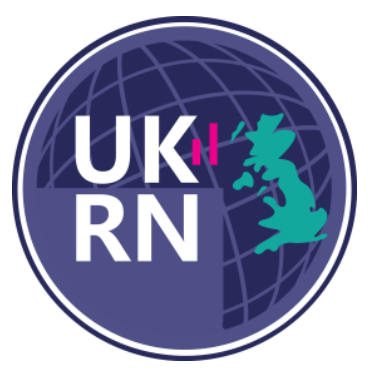

\section{What is open access (OA) for research publications?}

Open access (OA) is academic research that is published as digital, online, free of charge for reading, and free to reuse and share. Open access requires proper attribution of works to authors. Authors have several options when publishing academic research as open access:

1. Publish in a journal that makes the paper immediately freely available at the point of publication (Gold OA). Some journals require payment of an Article Processing Charge (APC) for Gold OA publishing. Journals can be either fully OA or are subscription journals with an OA option for authors (Hybrid).

2. Make a copy of your paper, usually the author's accepted manuscript after peer review, freely available in an open access repository (Green OA).

3. Choose to make early versions of the paper available (see UKRN Preprint Primer).

\section{Why would I disseminate my research as open access?}

Authors benefit from the dissemination of their research as OA by maximising the visibility and dissemination of research findings, thus increasing its readership and use (see Tennant et al. 2016). Openness promotes speed of dissemination, aids in access to research for reuse by others, and enables quality control and verification of the research (Jisc, 2016; see also Berlin Declaration, 2003). Universal open and barrier-free access to research benefits all knowledge users, including academia, businesses, charities, policymakers, researchers and institutions without or with limited funding, and the wider global society.

Dissemination of research as OA helps to reduce research waste by making research openly accessible, increases exposure of a researchers' work leading potentially to increased citations, offers access to a broader audience including those who cannot afford journal subscriptions, and situates the research across available literature.

\section{How do I disseminate my research as open access ${ }^{1}$}

1. Check your institutional and research funder policies around open access.

2. Select an OA journal for publication (see 'More Information': DOAJ) and ensure it aligns with OA policies ${ }^{1}$.

3. If you are considering publishing $O A$ in a fully or hybrid ${ }^{2} O A$ journal, check if you have funding available to pay any Article Processing Charges (APC).

4. Make early versions available (see UKRN Preprint Primer).

5. Deposit a copy (either the author accepted manuscript ${ }^{3}$ or Gold OA version) of your research in your institution's repository.

\footnotetext{
${ }^{1}$ Please note that open access practices may differ across disciplines.

2 It is worth noting, however, that hybrid journals are not compliant with Plan-S.

${ }^{3}$ The Author Accepted Manuscript (AAM) is the version that has been agreed with the editor/s at the point of acceptance. It is not the same as the copy-edited, typeset or published paper - these versions may be referred to as 'proofs' or 'versions of record'.
} 
There are several other ways that researchers can make their research open access, for example. by making copies of their research studies available on blogs, websites, or academic social media sites (refer to 'Rights, permissions and licensing', below).

\section{Rights, permissions and licensing}

When publishing in OA journals, authors (or institutions) often retain the copyright of their manuscripts and the journal applies a Creative Commons licence (typically CC BY). The CC BY licence allows for the distribution, remixing, tweaking, and building upon the licensed work, including for commercial purposes, as long as the original author is credited (Wild and Wilson 2013). It is the most liberal of the six CC licences in comparison with, for example, CC BY-ND (no derivatives, no modifications) and CC BY-NC (no commercial use). For example, you may wish to use your research in your teaching or reuse portions in future work, all of which would be governed by copyright. You can check for a sample publishing agreement or contact the editor of the journal and ask which rights are included as part of the author agreement.

Author re-use rights vary between journals. Read any Copyright Transfer Agreement (CTA) or similar document carefully before signing to review the applicable re-use rights. You may be able to negotiate the terms of the copyright (e.g., you may be able to retain full copyright and grant the publisher a licence to publish). To get to know your author rights you can read a useful guide written by the Canadian Association of Research Libraries (CARL) called the Guide to Author Rights (Last updated: April 2019).

Some journals impose an embargo period ${ }^{4}$ for articles deposited in a repository. Check individual journal permissions using Sherpa/RoMEO. Your institution librarian will be able to help you understand these permissions.

\section{Open access at your institution}

Institutions and organisations often apply their own OA policies and position statements that can mandate or make recommendations on faculty, staff and student open access publishing. The policy may require that research must be uploaded to institutional repositories.

Registries of institutional and organisational policies around OA include:

- SHERPA Juliet: maintains a list of research funding organisations' open access policies from around the world.

- $\quad$ ROARMAP (the Registry of Open Access Repository Mandates and Policies): contains records of institutional (as well as funder and organisational) mandates.

Institutional OA policies are often dictated by external policies and position statements such as Canada's Tri-Agency's Open Access Policy on Publications, and Europe's Plan-S guidelines for participating funders.

Consult OA help and information sites provided by your institution on issues such as:

- Institutional and/or funder commitments to OA.

- How to use your institutional repository.

- How to apply for funding, if available, to pay APCs.

- Copyright and licensing.

\footnotetext{
${ }^{4}$ Note that embargo periods are not compliant with Plan-S.
} 


\section{More information}

- $\quad$ Jisc have produced introductory and detailed guides for OA publishing (including guides for how OA can help with discovery, usage and impact of your work).

- Directory of Open Access Journals (DOAJ) is an online directory that indexes and provides access to high quality, open access, peer-reviewed journals.

- ThinkCheckSubmit is a great resource for checking if you are publishing your research in the right area, particularly if you have been approached by a journal and want to check its veracity.

- Center for Open Science have great resources for open research and provide tools, training and support for global open science.

\section{References}

About The Licenses - Creative Commons. (2019). Retrieved from https://creativecommons.org/licenses/

Berlin Declaration on Open Access to Knowledge in the Sciences and Humanities. (2003). Max Planck Gesellschaft. Retrieved from https://openaccess.mpg.de/BerlinDeclaration

Blanchett, H. (2016). An introduction to open access. Jisc. Retrieved from https://www.jisc.ac.uk/guides/an-introduction-to-open-access

Branch, C. (2016). Tri-Agency Open Access Policy on Publications - Science.gc.ca. Retrieved from http://www.science.gc.ca/default.asp?lang=En\&n=F6765465-1

CARL Guide to Author Rights (2019). Retrieved from CARL ABRC http://www.carlabrc.ca/wp-content/uploads/2019/05/CARL Guide author rights EN 2019.pdf

Directory of Open Access Journals. (2019). Retrieved from https://doaj.org/

Jacobs, N. and Blanchett, H. (2018). Open access: discovery, usage and impact. Jisc. Retrieved from https://www.jisc.ac.uk/guides/open-access-discovery-usage-andimpact

Jacobs, N. and Fahmy, S. (2018). Implementing open access. Jisc. Retrieved from https://www.jisc.ac.uk/guides/implementing-open-access

Plan-S. (2019). Retrieved from https://www.coalition-s.org/

ROARMAP eprints. (2019). Retrieved from http://roarmap.eprints.org/

Science Europe. (2019). Retrieved from https://www.scienceeurope.org/

SHERPA-JULIET - Research Funders' Open Access Policies. (2019). Retrieved from http://www.sherpa.ac.uk/juliet/

SHERPA-RoMEO - Publisher copyright policies and self-archiving. (2019). Retrieved from http://sherpa.ac.uk/romeo/index.php

Tennant JP, Waldner F, Jacques DC et al. The academic, economic and societal impacts of Open Access: an evidence-based review [version 3; peer review: 4 approved, 1 
approved with reservations]. F1000Research 2016, 5:632

https://doi.org/10.12688/f1000research.8460.3

The Center for Open Science. (2019). Retrieved from https://cos.io/

ThinkCheckSubmit. (2019). Retrieved from https://thinkchecksubmit.org/

Wild, J., Rowan, W. (2013). CC BY: what does it mean for scholarly articles? Retrieved from http://openaccess.ox.ac.uk/2013/06/13/cc-by-what-does-it-mean-for-scholarlyarticles-3/

Reviewed by Jon Tennant (0000-0001-7794-0218). Edited by Emma L Henderson (0000-0002-5396-2321) and Jackie Thompson (0000-0003-2851-3636).

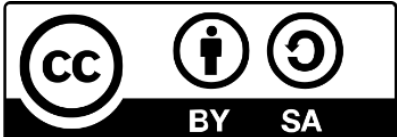

This work is licensed under a Creative Commons Attribution-ShareAlike 4.0 International License. 